\title{
Treatment protocols and management of retained fetal membranes in cattle by rural practitioners in Belgium
}

\author{
Justine Eppe $^{\mathrm{a}}$, Thomas Lowie ${ }^{\mathrm{b}}$, Geert Opsomer ${ }^{\mathrm{b}}$, Giles Hanley-Cook ${ }^{\mathrm{c}}$, Maya Meesters ${ }^{\mathrm{b}}$, \\ Philippe Bossaert ${ }^{\mathrm{a}, *}$ \\ ${ }^{a}$ Clinical Department of Production Animals, University of Liège, Quartier Vallée 2, Avenue de Cureghem 7A-7D, Liège, 4000, Belgium \\ ${ }^{\mathrm{b}}$ Department of Reproduction, Obstetrics and Herd Health, Faculty of Veterinary Medicine, Ghent University, Salisburylaan 133, Merelbeke, 9820, Belgium \\ ${ }^{\mathrm{c}}$ Department of Food Technology, Safety and Health, Faculty of Bioscience Engineering, Ghent University, Coupure 653, Ghent, 9000, Belgium
}

\section{A R T I C L E I N F O}

\section{Keywords:}

Retained fetal membranes

Antibiotic treatment

Cattle

Post-partum

\begin{abstract}
A B S T R A C T
Retained fetal membranes (RFM) is a frequent postpartum disorder in cattle causing considerable economic losses, and a common indication for antibiotic (AB) administration. There is controversy with regard to the treatment of RFM, and scientific recommendations are often in conflict with current legislation on $A B$ use and practical routines in the field.

The aim of this study was to assess the therapeutic approaches of RFM by Belgian rural veterinarians. A digital survey was sent to 468 Belgian veterinarians; 149 complete questionnaires (Wallonia: 78; Flanders: 71) were obtained. Survey questions captured socio-demographic characteristics, case definition, therapeutic approaches and treatment options for RFM. Questions on treatment were duplicated for dairy and beef cattle.

When confronted with dairy cows suffering from RFM without fever, $35.6 \%$ of vets do not treat with $\mathrm{AB}$, while the majority administers $\mathrm{AB}$, either intrauterine (47.6\%), systemically (10.7\%) or both (6.1 \%). Dairy cows with RFM and fever receive a systemic (33.5 \%), intrauterine (2.7\%) or combined (61.8\%) AB treatment. For a beef cow with RFM without fever, $21.5 \%$ of vets prefer no AB treatment, while others prefer an intrauterine (24.2\%), systemic (24.8\%), combined (29.5\%) AB treatment. Beef cows with RFM and fever receive AB from the large majority of vets, by systemic (34.9\%) or combined (56.3\%) administration. In case of a parenteral treatment, benzylpenicillin, amoxicillin and ampicillin are by far the most frequently used molecules; only a minority of vets use cephalosporins. Manual placental removal is attempted by $93.9 \%$ of the respondents.

These results demonstrate that there is room for improvement when considering the treatment protocols of RFM. Many veterinarians use AB in RFM cows not presenting symptoms of general illness, or administer intrauterine $\mathrm{AB}$ in cows with or without clinical signs of illness. Concerning the molecules of choice, practical routines are largely in line with national $\mathrm{AB}$ recommendations. Beef cows suffering from RFM are treated more rigorously than dairy cows, regardless of their rectal temperature.
\end{abstract}

\section{Introduction}

Retained fetal membranes (RFM) in cattle is defined as the nonexpulsion of fetal membranes beyond $24 \mathrm{~h}$ after calving (Fourichon et al., 2000; Bourne et al., 2006; Beagley et al., 2010). Gohary and LeBlanc (2018) estimated the economic cost of a RFM case to be $\$ 297$, due to production losses, treatment costs, reproductive disorders and increased culling risk. Indeed, cows with RFM are more likely to develop secondary health problems that require treatment, such as puerperal metritis in the short term (Dubuc et al., 2010) or displaced abomasum in the long term (Gröhn et al., 1995). Puerperal metritis is defined as the presence of an abnormal, fetid smelling vaginal discharge, an enlarged uterus and often systemic illness between 0 and 21 days post-partum (Sheldon, 2004; Sheldon et al., 2009). The production losses caused by RFM alone are estimated to be $753 \mathrm{~kg}$ of milk per lactation, with an additional $259 \mathrm{~kg}$ if puerperal metritis develops (Dubuc et al., 2011). Furthermore, cows with RFM have an increased risk for delayed cyclicity and lower pregnancy rates (Peters and Laven, 1996; Gröhn and Rajala-Schultz, 2000). The average annual incidence of RFM varies from 3 to $10-12 \%$, but is highly variable between farms and can reach up to

\footnotetext{
* Corresponding author.

E-mail address: p.bossaert@uliege.be (P. Bossaert).
} 
30 \% (Kimura et al., 2002; Bourne et al., 2006; Drillich et al., 2006b).

Despite the high incidence and considerable economic impacts, there is currently no consensus on the treatment of RFM. Several treatment options for RFM exist, including manual removal, intrauterine antibiotic (AB) therapy, systemic $\mathrm{AB}$ therapy and hormone treatment (Peters and Laven, 1996; Beagley et al., 2010; Pyörälä et al., 2014). Recently developed or future treatment options include ozone treatment (Djuricic et al., 2012; Imhof et al., 2019) and collagenase injection in the umbilical arteries (Guérin et al., 2004). In a clinical trial comparing four therapeutic approaches in over 500 RFM cases (Drillich et al., 2006a), manual removal of the placenta, preventive intrauterine $\mathrm{AB}$ administration, or the combination of both appeared to have only marginally positive effects on the risks of puerperal metritis, and no effects on reproductive performance, when compared to systemic $\mathrm{AB}$ treatment in selected cases of systemic illness. The same research group (Drillich et al., 2006b) found no advantage in the disease evolution or reproductive performance of RFM cows receiving preventive systemic $A B$ therapy (i.e., regardless of illness), compared to selective systemic $A B$ therapy for cows. Altogether, these studies suggest $A B$ administration, preferably systemically, for cows presenting systemic illness as the preferred therapeutic approach, without preventive intrauterine or systemic $\mathrm{AB}$ administration or manual placenta removal (Drillich et al., 2006a; Lima et al., 2014).

The most common germ identified in uterine swabs from puerperal metritis cows is Escherichia coli, alone or in combination with Gram positive cocci, Fusobacterium necrophorum, Clostridium spp. or Trueperella pyogenes (Ordell et al., 2016). Ceftiofur is the most documented AB molecule in clinical trials on RFM and puerperal metritis treatments (Drillich et al., 2003, 2006a, 2006b; Haimerl et al., 2017). However, in the current societal context, the routine use of a third generation cephalosporin can no longer be justified: according to the Belgian Centre of Expertise on AntiMicrobial Consumption and Resistance in Animals (AMCRA, 2020a, 2020b), ceftiofur is regarded as a molecule of critical importance, for which the use should be restricted unless an antibiogram indicates its need. Penicillin, ampicillin and oxytetracyclin are suggested in the literature as alternatives for ceftiofur for the systemic treatment of puerperal metritis (Lima et al., 2014; Pyörälä et al., 2014).

Finally, it should be noted that the Belgian Blue (BB) breed, which routinely undergoes elective caesarian section (CS), is the predominant beef breed in Belgium (Djebala et al., 2019). The risk for complications (e.g. RFM) and associated economic losses might be very different in an incised uterus, and therefore veterinarians' treatment routines might differ from their approach in dairy cows. However, to the best of our knowledge, no information is currently available on the treatment habits for BB cows suffering from RFM.

The aim of our study was to take stock of the treatment habits and decision-making criteria of Belgian rural veterinarians when treating dairy and beef cows suffering from RFM, and to investigate whether these habits are coherent with current scientific literature and national recommendations on $\mathrm{AB}$ use.

\section{Materials and methods}

The present study is based on a survey, which resulted from collaboration between Ghent University and the University of Liège. The questionnaire containing 54 questions was offered on an online platform (LimeSurvey) between October and December 2019, and shared through e-mail listings of referring veterinarians of the University Veterinary Clinics in Ruminants in Ghent (194 rural veterinarians contacted by email) and Liège (274 rural veterinarians contacted by e-mail). In addition, a call for the Flemish survey was shared through the monthly newsletters of DGZ (Dierengezondheidszorg Vlaanderen) addressed to cattle veterinarians.

The questionnaire was divided into six main sections: 1) demographic information, 2) case definition of RFM, 3) therapeutic approach, 4) treatment options, 5) risk factors for RFM and 6) preventive measures against RFM. In the present manuscript, only the results of the demographic variables, case definition, therapeutic approach and treatment options will be discussed; the corresponding questions are displayed in Appendix 1. Several question types were used, and veterinarians had the opportunity to give additional clarification to certain questions. The demographic variables section contained multiple-choice questions with regard to sex (male or female), university of graduation (Liège, Ghent or other) and years of practical experience (under 10, 11-20, 21-30, above 30). Region (Flanders or Wallonia) in which the respondent was practicing was included as an additional demographic variable. In the case definition section, a multiple-choice question was asked about the duration of non-expulsion with regard to the definition of RFM ( $>6 \mathrm{~h},>12 \mathrm{~h},>24 \mathrm{~h},>36 \mathrm{~h}$ or $>48 \mathrm{~h}$ ). The therapeutic approach section contained multiple-choice questions about diagnostic practices (taking temperature and performing a vaginal exploration: always, sometimes or never) and decisive elements for therapeutic decisions (fever, anorexia, abdominal straining, milk drop, dehydration). The treatment option section contained a multiple-choice question on manual removal (no, manual traction only, manual traction and detachment). Additionally, a multiple-choice question was asked on the route of $\mathrm{AB}$ administration (none, intrauterine, systemic, and combined) when consulting a RFM dairy cow with or without fever. Questions about $\mathrm{AB}$ treatment were duplicated for beef cattle, for whom an additional administration option was included (intraperitoneal or other routes). Furthermore, 5-point Likert scale questions were asked about the administration (1: never; 2 : rarely; 3: sometimes; 4: often; 5: always) of different molecules for intrauterine use (tetracyclins, cephapirine, water with antiseptics, povidone-iodine solution) and systemic use (tetracyclins, $\beta$-lactams: benzylpenicillin, amoxicillin and ampicillin, trimethoprim-sulfadiazine, macrolides, aminoglycosides alone or in combination, cephalosporins). In the Flemish questionnaire, a further distinction was made between 1st generation and 3rd generation cephalosporins. Finally, 5-point Likert scale questions were asked about the preference (1: never; 2: rarely; 3: sometimes; 4: often; 5: always) for hormonal treatment (synthetic prostaglandins, natural prostaglandins, oxytocin, oxytocin long acting, GnRH).

Data management and statistical analyses were conducted in Stata version 14.2 (StataCorp, 2015). Descriptive statistics [median (interquartile range) for ordinal variables and $n(\%)$ for categorical variables] were carried out. Furthermore, as a sensitivety analysis, the influence of demographic variables (sex, years of experience, university of graduation, region) on the outcomes were analyzed. For ordinal dependent variables (Likert scales, score of preference), bivariate ordered logistic regression models were fitted, including the socio-demographic variables as independent variables. For binary outcomes (yes or no, dummy variables for multiple choice questions), bivariate logistic regression models were fitted, including the same socio-demographic variables as covariates/predictors.

Due to the lack of a regional effect on the responses $(<10 \%$ changein-estimate (CIE) criterion for odds ratios (ORs) and all $P>0.05$ ), Flemish and Walloon survey data were pooled in order to increase statistical power.

A two-sided significance level of $P<0.05$ was applied for all analyses.

\section{Results}

\subsection{Demographic variables}

A total of 149 completely filled in questionnaires were obtained, of which 78 by Walloon and 71 by Flemish veterinarians. Walloon respondents were all reached by e-mail, while Flemish respondents were reached by e-mail $(n=59)$ or the DGZ newsletter $(n=12)$.

The university of graduation of the respondents was Ghent (48.3\%), Liège $(50.4 \%)$ and Utrecht $(1.3 \%)$. The majority of respondents $(83.9$ $\%)$ were male. The years of experience of the responding vets have been 
categorized into: $<10$ years $(30.9 \%), 11-20$ years $(17.5 \%), 21-30$ years $(22.1 \%)$ and $>30$ years $(29.5 \%)$.

The ORs of bivariate (ordered) logistic regression models (including sex, years of experience, university of graduation) were lower than our $10 \%$ CIE criterion and non-significant (all $P>0.05$ ). Therefore, no descriptive subgroup analyses of study outcomes were conducted for available socio-demographic variables.

\subsection{Case definition}

The large majority of veterinarians (71.8\%) define a case of RFM as a non-expulsion of the placenta beyond $24 \mathrm{~h}$ after calving, compared to other categories (>6 h: $2.1 \%$; >12 h: $22.2 \%$; > 36 h: $2.6 \%$; >48 h: 1.3 $\%)$.

\subsection{Therapeutic approach}

Considering the diagnosis, $64.5 \%$ of the surveyed practitioners always take the temperature of a cow with RFM, while $8.7 \%$ never do and $26.8 \%$ sometimes do. In the comments sections, its decisive value for the treatment choice was mentioned as the main reason for taking the temperature. A vaginal exploration is systematically done by the majority of respondents $(73.8 \%$ ), while $7.4 \%$ never do so and $18.8 \%$ sometimes do. The main motivation to perform a vaginal examination is to exclude vaginal lesions, to confirm the diagnosis of RFM, to check if the placenta is loose enough and to attempt manual removal of the placenta.

According to the respondents, a recently calved cow is considered to have fever when her temperature is above $39{ }^{\circ} \mathrm{C}(30.9 \%), 39.5^{\circ} \mathrm{C}(59$ $\%)$ or $40{ }^{\circ} \mathrm{C}(10.1 \%)$. The presence or absence of fever influences the treatment of RFM for $84.6 \%$ of the respondents. Many veterinarians marked other criteria influencing the treatment decision, such as, in order of importance, anorexia, abdominal straining and milk drop.

\subsection{Treatment options}

A large majority (93.9\%) of practitioners attempt manual removal of the placenta; $52.3 \%$ only apply gentle traction and $41.6 \%$ try to physically detach the placenta from the caruncular crypts.

When confronted with dairy cows with RFM without fever (Fig. 1), $35.6 \%$ of vets do not treat with $\mathrm{AB}$; the other vets administer $\mathrm{AB}$, either locally, i.e. intrauterine (47.6\%), systemically (10.7\%) or both (6.1\%). When consulting a dairy cow with RFM and fever (Fig. 1), the large majority of vets treat with $\mathrm{AB}$, either by combined (61.8\%), systemic (33.5 \%) or local administration (2.7\%), while $2 \%$ do not administer

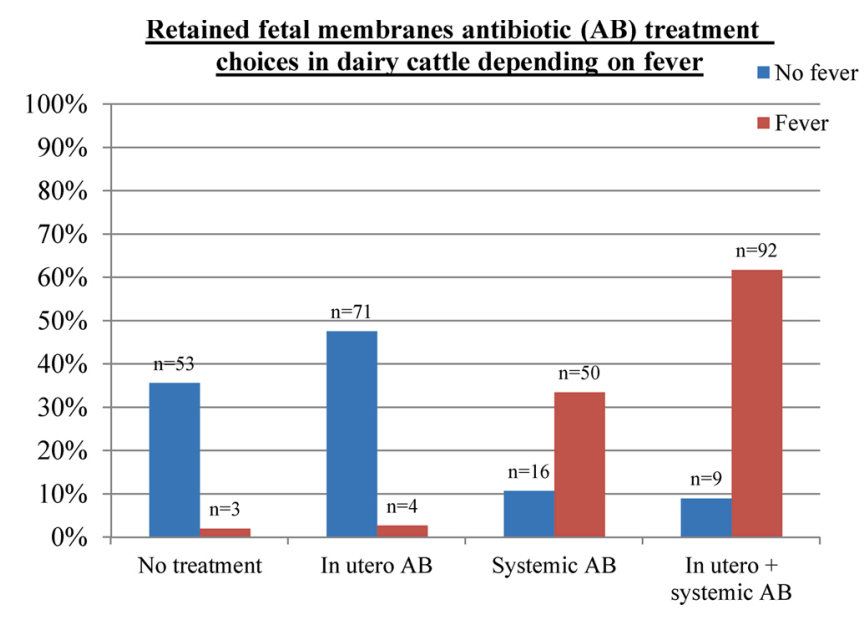

Fig. 1. Antibiotic $(\mathrm{AB})$ treatment choices for retained fetal membranes in dairy cattle depending on the presence or absence of fever.
AB. When seeing a beef cow with RFM without fever (Fig. 2), $21.5 \%$ of vets prefer no $\mathrm{AB}$ treatment; the other respondents apply $\mathrm{AB}$, either locally (24.2\%), systemically (24.2\%), combined (29.5\%) or via another administration route (intraperitoneally; $0.6 \%$ ). Beef cows with RFM and fever (Fig. 2) receive $\mathrm{AB}$ from the large majority of vets, either systematically (34.9\%), intrauterine (0.7 \%), or combined (56.3\%), or via another $\mathrm{AB}$ administration route (7.4\%; intraperitoneally), while $0.7 \%$ of respondents do not administer any $\mathrm{AB}$.

Respondents were asked to rank a number of molecules in order of preference (1: never used, 2: rarely used, 3: sometimes used, 4: often used, 5: always used), for local or systemic use. Considering intrauterine treatment, the ranking in declining order of preference was: tetracyclines, water with antiseptics, povidone-iodine solution and cefapirin. The $A B$ molecules used for systemic treatment that received the highest preference score ( 4 or 5), were: $\beta$-lactams (benzylpenicillin, amoxicillin and ampicillin) (dairy: $75.2 \%$; beef: $79.8 \%$ ), tetracyclins (dairy: 29.5 \%; beef: $35.6 \%$ ), trimethoprim-sulfadiazine (dairy: $20.2 \%$; beef: 12.8 $\%$ ), aminoglycosides alone or in combination (dairy: $12.7 \%$; beef: 19.5 $\%$ ), cephalosporins (dairy: $20.6 \%$ for all cephalosporins, $23.9 \%$ for 1 st generation, $4.2 \%$ for 3rd generation; beef: $9 \%$ for all cephalosporins, 4.2 $\%$ for 1 st generation, $5.6 \%$ for 3rd generation) and macrolides (dairy: $5.4 \%$; beef: $6 \%$ ). Only the Flemish questionnaire made a further distinction between 1st generation and 3rd generation cephalosporins. Results of these questions are presented in Tables 1 and 2.

The same ranking was proposed for the use of hormones in the treatment of RFM, more specifically synthetic and natural prostaglandins, GnRH, oxytocin and long acting oxytocin. A large majority of respondents rarely or never use hormones for RFM treatment: the percentage of veterinarians attributing a score of 1 and 2 was $70.3 \%$ for synthetic prostaglandins, $63.5 \%$ for natural prostaglandins, $93.9 \%$ for $\mathrm{GnRH}, 55.4 \%$ for oxytocin, and $76.2 \%$ for long acting oxytocin.

\section{Discussion}

The results of our study demonstrate that $\mathrm{AB}$ are largely used for the treatment of RFM, in cows with (dairy: $98 \%$; beef: $99.3 \%$ ) and without fever (dairy: $64.4 \%$; beef: $78.5 \%$ ). Since the use of $A B$ stimulates the development of $A B$ resistance in bacteria (Chantziaras et al., 2013), veterinarians are encouraged to rationalize their $\mathrm{AB}$ treatments. This implies knowledge of pertinent clinical studies, defining in which conditions $\mathrm{AB}$ use can be avoided, and how $\mathrm{AB}$ can be applied correctly when necessary. Good veterinary practice also implies the adherence to national legislation. The AMCRA expertise center aims to reduce Belgian veterinary $A B$ use, especially for molecules of critical importance, and provides practical recommendations (AMCRA 2020a, 2020b). However, scientific literature, AMCRA recommendations, treatment routines by

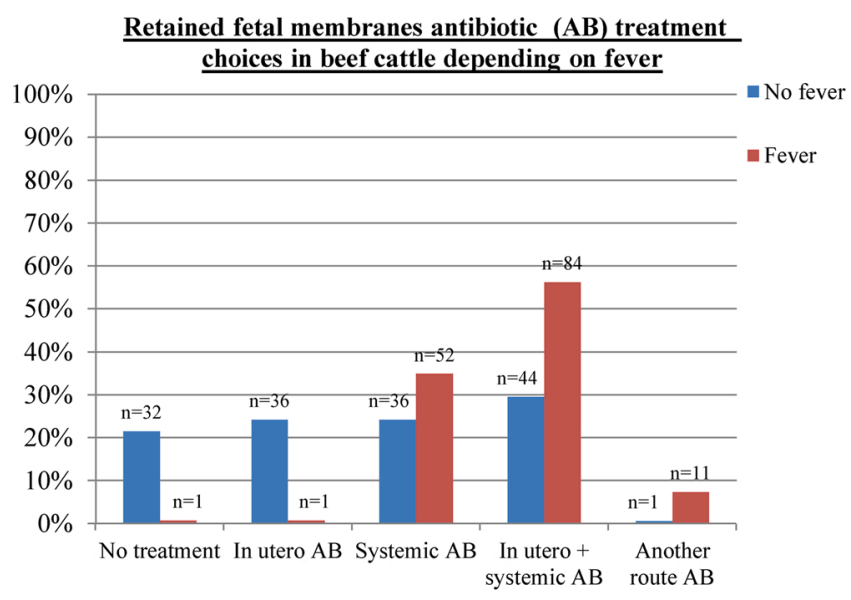

Fig. 2. Antibiotic $(\mathrm{AB})$ treatment choices for retained fetal membranes in beef cattle depending on the presence or absence of fever. 
Table 1

Preference scores for the molecule choice in case of systemic antibiotic treatment for retained fetal membranes in dairy cows 1: never used, 2: rarely used, 3: sometimes used, 4: often used, 5: always used. Results are expressed as the percentage of practitioners surveyed and as the number of answers/number of respondents. *Only the Flemish questionnaire made a further distinction between 1st and 3rd generation cephalosporins, while the Walloon questionnaire only covered cephalosporins, all classes combined.

\begin{tabular}{|c|c|c|c|c|c|}
\hline & \multicolumn{5}{|c|}{ Dairy cows } \\
\hline & 1 & 2 & 3 & 4 & 5 \\
\hline \multirow{3}{*}{ Tetracyclins } & $\begin{array}{l}36.2 \\
\%\end{array}$ & $20.8 \%$ & $\begin{array}{l}13.4 \\
\%\end{array}$ & $22.2 \%$ & $7.4 \%$ \\
\hline & $54 /$ & $31 /$ & $20 /$ & $33 /$ & $11 /$ \\
\hline & 149 & 149 & 149 & 149 & 149 \\
\hline \multirow{2}{*}{$\begin{array}{l}\text { Benzylpenicillin, amoxicillin } \\
\text { and ampicillin }\end{array}$} & $6.7 \%$ & $2.7 \%$ & $\begin{array}{l}15.4 \\
\%\end{array}$ & $57.7 \%$ & $\begin{array}{l}17.5 \\
\%\end{array}$ \\
\hline & $\begin{array}{l}10 / \\
149\end{array}$ & $4 / 149$ & $\begin{array}{l}23 / \\
149\end{array}$ & $\begin{array}{l}86 / \\
149\end{array}$ & $\begin{array}{l}26 / \\
149\end{array}$ \\
\hline \multirow{2}{*}{ Trimethoprim-sulfadiazine } & $\begin{array}{l}45.0 \\
\%\end{array}$ & $20.0 \%$ & $\begin{array}{l}14.8 \\
\%\end{array}$ & $17.5 \%$ & $2.7 \%$ \\
\hline & $\begin{array}{l}67 / \\
149\end{array}$ & $\begin{array}{l}30 / \\
149\end{array}$ & $\begin{array}{l}22 / \\
149\end{array}$ & $\begin{array}{l}26 / \\
149\end{array}$ & $4 / 149$ \\
\hline \multirow{2}{*}{ Macrolides } & $\begin{array}{l}64.4 \\
\%\end{array}$ & $20.1 \%$ & $\begin{array}{l}10.1 \\
\%\end{array}$ & $5.4 \%$ & $0.0 \%$ \\
\hline & $\begin{array}{l}96 / \\
149\end{array}$ & $\begin{array}{l}30 / \\
149\end{array}$ & $\begin{array}{l}15 / \\
149\end{array}$ & $8 / 149$ & $0 / 149$ \\
\hline \multirow{2}{*}{$\begin{array}{l}\text { Aminoglycosides alone or in } \\
\text { combination }\end{array}$} & $\begin{array}{l}51.7 \\
\%\end{array}$ & $24.2 \%$ & $\begin{array}{l}11.4 \\
\%\end{array}$ & $11.4 \%$ & $1.3 \%$ \\
\hline & $\begin{array}{l}77 / \\
149\end{array}$ & $\begin{array}{l}36 / \\
149\end{array}$ & $\begin{array}{l}17 / \\
149\end{array}$ & $\begin{array}{l}17 / \\
149\end{array}$ & $2 / 149$ \\
\hline \multirow[t]{2}{*}{ Cephalosporins* } & $\begin{array}{l}39.7 \\
\%\end{array}$ & $25.6 \%$ & $\begin{array}{l}14.1 \\
\%\end{array}$ & $16.7 \%$ & $3.9 \%$ \\
\hline & $31 / 78$ & $20 / 78$ & $11 / 78$ & $13 / 78$ & $3 / 78$ \\
\hline \multirow{2}{*}{$\begin{array}{l}\text { Cephalosporins 1rst } \\
\text { generation* }\end{array}$} & $\begin{array}{l}47.9 \\
\%\end{array}$ & $19.7 \%$ & $8.5 \%$ & $23.9 \%$ & $0.0 \%$ \\
\hline & $34 / 71$ & $14 / 71$ & $6 / 71$ & $17 / 71$ & $0 / 71$ \\
\hline \multirow[t]{2}{*}{ Cephalosporins 3rd generation* } & $\begin{array}{l}70.4 \\
\%\end{array}$ & $22.6 \%$ & $2.8 \%$ & $2.8 \%$ & $1.4 \%$ \\
\hline & $50 / 71$ & $16 / 71$ & $2 / 71$ & $2 / 71$ & $1 / 71$ \\
\hline
\end{tabular}

veterinarians and expectations by farmers are not always in line. In particular, concerning the treatment of RFM and puerperal metritis, the scientific literature often describes a systemic treatment with ceftiofur (Drillich et al., 2003, 2006a, 2006b; Haimerl et al., 2017), while the use of this molecule is strongly discouraged from a legislative point of view. The current survey is useful to identify treatment habits of veterinarians, to assess whether these habits are in line with the scientific literature and legislation, and to identify areas for improvement. We are not the first to take an interest in this issue, since a similar survey was recently published in Switzerland (Hehenberger et al., 2015). However, since the type of breed, the available products and the national legislation differ between countries, these data cannot be extrapolated to the Belgian context.

All regions and experience categories are well represented in our survey. Most of the responding practitioners are male. Demographic elements like sex, university of graduation, years of practical experience and region did not seem to influence the responses. Our study might have bias, because the cross-sectional nature of our data infers that our analysis might be hampered by omitted confounding and missing data (only complete questionnaires were analyzed). Another bias could be found in the $A B$ questions: cephalosporins were subdivided in first and third generation in the Flemish, but not the Walloon questionnaire.

There seems to be a consensus about the case definition of RFM: most practitioners apply the currently established definition of RFM as the non-expulsion of fetal membranes beyond $24 \mathrm{~h}$ after calving (Fourichon et al., 2000; Bourne et al., 2006; Beagley et al., 2010). The majority of respondents always take the temperature and perform a vaginal examination of a RFM patient. Fever, mostly defined as a rectal temperature above $39.5^{\circ} \mathrm{C}$, was generally recognized as a criterion for choice for treatment, as suggested in literature (Drillich et al., 2001; Lima et al.,
Table 2

Preference scores for the molecule choice in case of systemic antibiotic treatment for retained fetal membranes in beef cows 1: never used, 2: rarely used, 3: sometimes used, 4: often used, 5: always used. Results are expressed as the percentage of practitioners surveyed and as the number of answers/number of respondents. *Only the Flemish questionnaire made a further distinction between 1st and 3rd generation cephalosporins, while the Walloon questionnaire only covered cephalosporins, all classes combined.

\begin{tabular}{|c|c|c|c|c|c|}
\hline & \multicolumn{5}{|c|}{ Beef cows } \\
\hline & 1 & 2 & 3 & 4 & 5 \\
\hline \multirow{3}{*}{ Tetracyclins } & $30.2 \%$ & $18.1 \%$ & $\begin{array}{l}16.1 \\
\%\end{array}$ & $24.1 \%$ & $11.5 \%$ \\
\hline & $45 /$ & $27 /$ & 24/ & $36 /$ & $17 /$ \\
\hline & 149 & 149 & 149 & 149 & 149 \\
\hline \multirow{2}{*}{$\begin{array}{l}\text { Benzylpenicillin, amoxicillin } \\
\text { and ampicillin }\end{array}$} & $3.4 \%$ & $3.4 \%$ & $\begin{array}{l}13.4 \\
\%\end{array}$ & $53.0 \%$ & $26.8 \%$ \\
\hline & $5 / 149$ & $5 / 149$ & $\begin{array}{l}20 / \\
149\end{array}$ & $\begin{array}{l}79 / \\
149\end{array}$ & $\begin{array}{l}40 / \\
149\end{array}$ \\
\hline \multirow{2}{*}{ Trimethoprim-sulfadiazine } & $55.0 \%$ & $22.1 \%$ & $\begin{array}{l}10.1 \\
\%\end{array}$ & $10.1 \%$ & $2.7 \%$ \\
\hline & $\begin{array}{l}82 / \\
149\end{array}$ & $\begin{array}{l}33 / \\
149\end{array}$ & $\begin{array}{l}15 / \\
149\end{array}$ & $\begin{array}{l}15 / \\
149\end{array}$ & $4 / 149$ \\
\hline \multirow{2}{*}{ Macrolides } & $70.5 \%$ & $12.8 \%$ & $\begin{array}{l}10.7 \\
\%\end{array}$ & $4.7 \%$ & $1.3 \%$ \\
\hline & $\begin{array}{l}105 / \\
149\end{array}$ & $\begin{array}{l}19 / \\
149\end{array}$ & $\begin{array}{l}16 / \\
149\end{array}$ & $7 / 149$ & $2 / 149$ \\
\hline \multirow{2}{*}{$\begin{array}{l}\text { Aminoglycosides alone or in } \\
\text { combination }\end{array}$} & $43 \%$ & $20 \%$ & $\begin{array}{l}17.5 \\
\%\end{array}$ & $17.5 \%$ & $2 \%$ \\
\hline & $\begin{array}{l}64 / \\
149\end{array}$ & $\begin{array}{l}30 / \\
149\end{array}$ & $\begin{array}{l}26 / \\
149\end{array}$ & $\begin{array}{l}26 / \\
149\end{array}$ & $3 / 149$ \\
\hline \multirow{2}{*}{ Cephalosporins* } & $65.4 \%$ & $17.9 \%$ & $7.7 \%$ & $6.4 \%$ & $2.6 \%$ \\
\hline & $51 / 78$ & $14 / 78$ & $6 / 78$ & $5 / 78$ & $2 / 78$ \\
\hline \multirow{2}{*}{$\begin{array}{l}\text { Cephalosporins 1rst } \\
\text { generation* }\end{array}$} & $77.5 \%$ & $15.5 \%$ & $2.8 \%$ & $4.2 \%$ & $0.0 \%$ \\
\hline & $55 / 71$ & $11 / 71$ & $2 / 71$ & $3 / 71$ & $0 / 71$ \\
\hline \multirow{2}{*}{$\begin{array}{l}\text { Cephalosporins 3rd } \\
\text { generation* }\end{array}$} & $78.9 \%$ & $12.7 \%$ & $2.8 \%$ & $4.2 \%$ & $1.4 \%$ \\
\hline & $56 / 71$ & 9/71 & $2 / 71$ & $3 / 71$ & $1 / 71$ \\
\hline
\end{tabular}

2014; Pohl et al., 2016). Vaginal examination can be necessary to confirm the diagnosis, for instance when the fetal membranes are not externalized (Gilbert, 2018), but another important motive for vaginal exploration seems to be the manual removal of the placenta, which is done by a large majority of respondents. This practice of manual removal of the placenta does not seem to be a uniquely Belgian practice, since another recent study came to the same conclusion (Hehenberger et al., 2015). Manual placenta removal has proven to be ineffective to avoid systemic illness or improve reproductive performance (Drillich et al., 2006). The detachment of the cotyledons from the caruncular crypts should be discouraged, since it can worsen the situation by inflicting (micro-)lesions in the endometrium (Banerjee, 1966; Vandeplassche and Bouters, 1982; Bolinder et al., 1988). It is not known whether placenta removal by light traction has the same negative effects.

Systemic AB treatment of RFM in the absence of systemic illness has not proven to have any beneficial effects compared to a selective treatment (Drillich et al., 2006b), and should be discouraged. Nevertheless, the majority of veterinarians (64.4\%) initiate an $A B$ treatment in a dairy cow with RFM and no fever. We suggest that a considerable proportion of this $\mathrm{AB}$ use (and associated treatment costs) can be avoided without deleterious effects on the animal's wellbeing and performance, by a better selection of the cows truly needing an $\mathrm{AB}$ therapy. It should be noted that this selection ideally includes other elements of the clinical examination besides the presence or absence of fever, as also suggested by the respondents in the comments section.

As expected, the frequency of $\mathrm{AB}$ treatments increases when dairy cows with RFM also present fever. Remarkably, whereas $33.5 \%$ of respondents uniquely use the systemic route, almost two thirds of the respondents use the intrauterine administration route, alone or in combination with systemic $\mathrm{AB}$. In literature, intrauterine $\mathrm{AB}$ treatment for cows with RFM and fever seems to have very little added value when 
a systemic treatment is applied (Musah et al., 1987; Drillich et al., 2003; Kaitu'u et al., 2005; Goshen and Shpigel, 2006).

Intrauterine treatment of RFM with water and antiseptic solutions (e. g. povidone-iodine) remains common practice, but is controversial. Although widely used in mares with RFM (Threlfall et al., 2007; Burden et al., 2019), there is no evidence of its efficacy in cows. As also demonstrated in another recent study (Hehenberger et al., 2015), tetracyclines are the most commonly used molecules for intrauterine $\mathrm{AB}$ treatment. This is logical, since chlortetracyclines are the only registered $\mathrm{AB}$ molecules on the market in Belgium for local treatment of RFM (Gustin, 2020). The use of tetracyclines is however controversial because they may interfere with the natural intrauterine inflammatory/immune system (Moller, 1967; Eiler and Fecteau, 2007; Gilbert, 2018).

The most frequently used $\mathrm{AB}$ molecules to systemically treat RFM were $\beta$-lactams (benzylpenicillin, amoxicillin and ampicillin), followed by tetracyclines and trimethoprim-sulfadiazine. Ample description of ceftiofur in clinical studies (Drillich et al., 2003, 2006a, 2006b; Haimerl et al., 2017) might have generalized the use of this molecule for the treatment of RFM, although current national recommendations strongly discourage its use and stimulate the use of alternatives (AMCRA, 2020a, AMCRA, 2020b). While the first generation cephalosporins were regularly used by a quarter of the Flemish respondents, third generation cephalosporins were very rarely used. The majority of Walloon respondents rarely or never use any cephalosporins. Altogether, the molecule choice by Belgian veterinarians seems to be in line with the AMCRA recommendations. The most commonly isolated bacterium in puerperal metritis is Escherichia coli (Ordell et al., 2016). The use of ampicillin seems justified because of its efficacy against Escherichia coli (Lehtolainen et al., 2003); accordingly, satisfactory clinical results have been observed when treating metritis with ampicillin (Lima et al., 2014). According to a recent Swiss survey, the most widely used molecule was tetracycline, followed by penicillin (Hehenberger et al., 2015).

The same tendencies on RFM treatment were observed in beef cows. The majority of beef cows in Belgium are of the BB breed, which practically always calve via elective CS. A higher proportion of veterinarians seem to apply $A B$ in beef cows with RFM, with or without fever, compared to dairy cows. We hypothesize that this may be explained because an $\mathrm{AB}$ injection has already been administered on the day of CS (Djebala et al., 2019), because veterinarians fear peritonitis when a cow develops RFM after CS, and because milk withdrawal times are not an issue in $\mathrm{BB}$ cows. The most frequently used molecules for systemic treatment are $\beta$-lactams, which are also the drug of choice for $\mathrm{AB}$ treatment during elective CS (Djebala et al., 2019). Remarkably, $7.4 \%$ of respondents treating a beef cow with RFM and fever use the intraperitoneal route, which is popular also during elective CS (Djebala et al., 2019). This seems to confirm the fear for peritonitis as a complication of RFM after CS. However, intraperitoneal use of $A B$ is not registered in Belgium and its effectiveness and pharmacokinetics are unknown, and therefore this injection route seems hard to justify.

Hormonal treatments were not frequently used by the practitioners participating in our study. This tendency is in accordance with the literature, where no convincing arguments could be found to promote hormonal treatment for RFM. Indeed, the use of oxytocin alone (Garcia et al., 1992; Palomares et al., 2010) or in combination with prostaglandins (Garcia et al., 1992) following calving did not decrease the incidence of RFM $24 \mathrm{~h}$ later. Also, there is no evidence that these hormonal treatments result in a faster expulsion of the retained membranes (Frazer, 2005).

Finally, the question remains whether or not we should treat cows with RFM and puerperal metritis at all. For obvious ethical reasons (not treating a sick cow with RFM and puerperal metritis), negative control studies are controversial and scarce. Only one study has included a negative control group that did not receive any treatment for RFM and clinical metritis (Goshen and Shpigel, 2006). This study did not prove the benefit of the use of intrauterine $\mathrm{AB}$ for RFM compared to no treatment. Pohl et al. (2016) have concluded that an initial 3 day ketoprofen treatment in the case of puerperal metritis could be helpful in reducing the total $\mathrm{AB}$ use in dairy cows since roughly $39 \%$ of cows recovered clinically without ceftiofur, although $61 \%$ of cows still required an $A B$ treatment after ketoprofen. The latter study could be a cautious step towards a reduced $\mathrm{AB}$ use.

\section{Conclusion}

An opportunity exists to lower and rationalize $A B$ use in the case of bovine RFM. According to current scientific literature, the use of $A B$ in the treatment of RFM in cattle should be limited to cows with fever and, in these cases, a systemic treatment should be preferred. Many veterinarians apply $A B$ in RFM cows not presenting clinical illness, which is discouraged in literature. Intrauterine $\mathrm{AB}$ administration is a common habit to treat RFM cows (with or without illness), which leads to higher $\mathrm{AB}$ use and their associated costs, although it has not been proven to be beneficial for the cows' short-term health risks or reproductive performance on the long term. Manual removal of the placenta is still a common practice among Belgian practitioners, although it has not proven to be effective and carries potential disadvantages. Concerning the molecule choice, practical routines are in line with national $\mathrm{AB}$ regulations. Beef cows with RFM are treated with $A B$ more frequently than dairy cows, which can be explained by the more severe complication risks when RFM develops in an incised uterus. Changing treatment routines will require raising awareness among veterinary students, practitioners and farmers on the subject of prudent antibiotic use and better communication of relevant clinical field trials.

\section{Funding}

This research did not receive any specific grant from funding agencies in the public, commercial, or not-for-profit sectors.

\section{Declaration of Competing Interest}

The authors declare that they have no conflict of interest.

\section{Acknowledgements}

We thank the rural practitioners who answered our survey and everyone who contributed to the correction and the improvement of the manuscript

\section{Appendix A. 1: Sections 1-4 of the questionnaire}

Section 1: demographic information

1. What is your sex?

- Female

- Male 
2. Where did you finish your studies? If "elsewhere", please specify as a comment

- Liège

- Ghent

- Elsewhere

Make the comment of your choice here:

3. How many years of practical experience do you have?

- Less than 10

- 11-20

- 21-30

- Above 30

Section 2: case definition of RFM

1. After how many hours do you consider a cow to suffer from retained fetal membranes?

- $>6 \mathrm{~h}$

- $>12 \mathrm{~h}$

- $>24 \mathrm{~h}$

- $>36 \mathrm{~h}$

- $>48 \mathrm{~h}$

Section 3: therapeutic approach

1. When you are consulted for a cow with retained fetal membranes, do you take her temperature? Please explain briefly

- Never, because

- Always, because

- Sometimes, because

Make the comment of your choice here:

2. When you are consulted about a cow with retained fetal membranes, do you do a vaginal examination? Please explain briefly

- Never, because

- Always, because

- Sometimes, because

Make the comment of your choice here:

3. When you are consulted for a cow with retained fetal membranes, do you try to manually remove the placenta?

- Yes, I only apply traction without trying to detach the placenta from the endometrium

- Yes, and if necessary I try to detach the placenta from the endometrium.

- No

4. At what temperature do you consider a cow with retained fetal membranes to have a fever?

- Starting at $39^{\circ} \mathrm{C}$

- Starting at $39.5^{\circ} \mathrm{C}$

- Starting at $40{ }^{\circ} \mathrm{C}$

5. Is the presence or absence of fever a treatment criterion for you?

- Yes

- No

6. Apart from fever, are there any other criteria that define your choice of treatment? (several answers possible)

- No

- Dehydration

- Anorexia

- Milk drop 
- Abdominal straining

- Another else

Section 4: treatment options

1. In a dairy cow with retained fetal membranes and no fever, which antibiotic therapy do you prefer? Clarify your answer

- No antibiotic treatment

- Antibiotics by uterine route only

- Antibiotics by systemic route only

- Uterine and general antibiotics

Make the comment of your choice here:

2. In a beef cow with retained fetal membranes and no fever, which antibiotic therapy do you prefer? Clarify your answer

- No antibiotic treatment

- Antibiotics by uterine route only

- Antibiotics by systemic route only

- Uterine and general antibiotics

- Other (intraperitoneal, other combinations)

Make the comment of your choice here:

3. In a dairy cow with retained fetal membranes and fever, which antibiotic do you prefer? Clarify your answer

- No antibiotic treatment

- Antibiotics by uterine route only

- Antibiotics by systemic route only

- Uterine and general antibiotics

Make the comment of your choice here:

4. In a beef cow with retained fetal membranes and fever, which antibiotic do you prefer? Clarify your answer

- No antibiotic treatment

- Antibiotics by uterine route only

- Antibiotics by systemic route only

- Uterine and general antibiotics

- Other (intraperitoneal, other combinations)

Make the comment of your choice here:

5. When treating a cow with intrauterine treatment for retained fetal membranes, which of the following products do you use? $(1=$ never, $2=$ rarely, $3=$ sometimes, $4=$ often, $5=$ always)

\begin{tabular}{cccccc}
\hline & 1 & $\mathbf{2}$ & $\mathbf{3}$ & $\mathbf{4}$ & $\mathbf{5}$ \\
\hline Tetracyclins (i.e. oxytetracyclin, chlortetracyclins) & 0 & 0 & 0 & 0 & 0 \\
Cefapirin & 0 & 0 & 0 & 0 & 0 \\
Instillation of an iodine solution & 0 & 0 & 0 & 0 & 0 \\
Wash with a few litres of water without or with another antiseptic & 0 & 0 & 0 & 0 & 0 \\
product & & & & & \\
\end{tabular}


6. When you give general antibiotic therapy to a dairy cow with retained fetal membranes, which of the following products do you use? $(1=$ never, $2=$ rarely, 3 = sometimes, $4=$ often, 5 = always)

\begin{tabular}{cccccc}
\hline & 1 & $\mathbf{2}$ & $\mathbf{3}$ & $\mathbf{4}$ & $\mathbf{5}$ \\
\hline Tetracyclins (i.e. oxytetracyclins) & 0 & 0 & 0 & 0 & 0 \\
3-lactams (i. e. procaine benzylpenicillin, ampicillin, amoxicillin) & 0 & 0 & 0 & 0 & 0 \\
Trimethoprim-sulfadiazine & 0 & 0 & 0 & 0 & 0 \\
Macrolides (i.e. tylosine) & 0 & 0 & 0 & 0 & 0 \\
Aminoglycosids (alone or in combination; i.e. neomycin, & 0 & 0 & 0 & 0 & 0 \\
neomycin + penicillin, streptomycine + penicillin, gentamycine, & & & & & \\
lincomycine + spectinomycine) & & & & & \\
Cephalosporins (Walloon questionnaire) & 0 & 0 & 0 & 0 & 0 \\
Cephalosporins 1rst generation (Flemish questionnaire) & 0 & 0 & 0 & 0 & 0 \\
Cephalosporins 3rd generation (Flemish questionnaire) & 0 & 0 & 0 & 0 & 0 \\
\hline
\end{tabular}

7. When you give general antibiotic therapy to a beef cow with retained fetal membranes, which of the following products do you use? $(1=$ never, $2=$ rarely, 3 = sometimes, $4=$ often, 5 = always)

\begin{tabular}{cccccc}
\hline & 1 & $\mathbf{2}$ & $\mathbf{3}$ & $\mathbf{4}$ & $\mathbf{5}$ \\
\hline Tetracyclins (i.e. oxytetracyclins) & 0 & 0 & 0 & 0 & 0 \\
B-lactams (i. e. procaine benzylpenicillin, ampicillin, amoxicillin) & 0 & 0 & 0 & 0 & 0 \\
Trimethoprim-sulfadiazine & 0 & 0 & 0 & 0 & 0 \\
Macrolides (i.e. tylosine) & 0 & 0 & 0 & 0 & 0 \\
Aminoglycosids (alone or in combination; i.e. neomycin, neomycin + & 0 & 0 & 0 & 0 & 0 \\
penicillin, streptomycine + penicillin, gentamycine, lincomycine + & & & & \\
spectinomycine) & & & & \\
Cephalosporins (Wallon questionnaire) & 0 & 0 & 0 & 0 & 0 \\
Cephalosporins 1rst generation (Flemish questionnaire) & 0 & 0 & 0 & 0 & 0 \\
Cephalosporins 3rd generation (Flemish questionnaire) & 0 & 0 & 0 & 0 & 0 \\
\hline
\end{tabular}

8. When you treat a dairy cow with retained fetal membranes with hormonal products, which of the following products do you use? ( $1=$ never, $2=$ rarely, 3 = sometimes, 4 = often, 5 = always)

\begin{tabular}{cccccc}
\hline & $\mathbf{1}$ & $\mathbf{2}$ & $\mathbf{3}$ & $\mathbf{4}$ & $\mathbf{5}$ \\
\hline Synthetic prostaglandins (i.e. cloprostenol, alphaprostol) & 0 & 0 & 0 & 0 & 0 \\
Natural prostaglandins (i.e. dinoprost) & 0 & 0 & 0 & 0 & 0 \\
GnRH (i.e. gonadorelin, buserelin) & 0 & 0 & 0 & 0 & 0 \\
Oxytocin & 0 & 0 & 0 & 0 & 0 \\
Oxytocin long acting (carbetocine) & 0 & 0 & 0 & 0 & 0 \\
\hline
\end{tabular}


9. When you treat a beef cow with retained fetal membranes with hormonal products, which of the following products do you use? ( $1=$ never, $2=$ rarely, 3 = sometimes, 4 = often, 5 = always)

\begin{tabular}{ccccccc}
\hline & $\mathbf{1}$ & $\mathbf{2}$ & $\mathbf{3}$ & $\mathbf{4}$ & $\mathbf{5}$ \\
\hline Synthetic prostaglandins (i.e. cloprostenol, alphaprostol) & 0 & 0 & 0 & 0 & 0 \\
Natural prostaglandins (i.e. dinoprost) & & 0 & 0 & 0 & 0 & 0 \\
GnRH (i.e. gonadorelin, buserelin) & 0 & 0 & 0 & 0 & 0 \\
Oxytocin & 0 & 0 & 0 & 0 & 0 \\
Oxytocin long acting (carbetocine) & & 0 & 0 & 0 & 0 & 0 \\
\end{tabular}

\section{References}

Antimicrobial Consumption and Resistance in Animals (AMCRA), 2020a.Traitement antibactérien péri-opératoire. (accessed 30 November 2020) Available at: https:// formularium.amcra.be/i/79 .

Antimicrobial Consumption and Resistance in Animals (AMCRA), 2020b.Traitement antibactérien de la métrite aigue. (accessed 30 November 2020) Available at: https://formularium.amcra.be/i/65 .

Banerjee, A.K., 1966. A study of the action of terramycin on the bacterial flora of the uterus in cattle following retained placenta. Indian Vet. J. 43, 319-326. PMID: 5949470.

Beagley, J.C., Whitman, K.J., Baptiste, K.E., Scherzer, J., 2010. Physiology and treatment of retained fetal membranes in cattle. J. Vet. Intern. Med. 24, 261-268.

Bolinder, A., Seguin, B., Kindahl, H., Bouley, D., Otterby, D., 1988. Retained fetal membranes in cows: manual removal versus nonremoval and its effect on reproductive performance. Theriogenology 30, 45-56. https://doi.org/10.1016/ 0093-691X(88)90262-2.

Bourne, N., Laven, R., Wathes, D.C., Martinez, T., McGowan, M., 2006. A meta-analysis of the effects of Vitamin E supplementation on the incidence of retained foetal membranes in dairy cows. Theriogenology 67, 494-501. https://doi.org/10.1016/j theriogenology.2006.08.015.

Burden, C.A., Meijer, M., Pozor, M.A., Macpherson, M.L., 2019. Fetal membrane removal in the mare: proactive versus reactive approaches. Vet. Clin. North Am. - Equine Pract. 35, 289-298. https://doi.org/10.1016/j.cveq.2019.04.004.

Chantziaras, I., Bouen, F., Callens, B., Dewulf, G., 2013. Correlation between veterinary antimicrobial use and antimicrobial resistance in food-producing animals: a report on seven countries. J. Antimicrob. Chemother. 69, 827-834. https://doi.org/ 10.1093/jac/dkt443.

Djebala, S., Moula, N., Bayrou, C., Sartelet, A., Bossaert, P., 2019. Prophylactic antibiotic usage by Belgian veterinarians during elective caesarean section in Belgian blue cattle. Prev. Vet. Med. 172, 104785 https://doi.org/10.1016/j. prevetmed.2019.104785.

Djuricic, D., Vince, S., Ablondi, M., Dobranic, T., Samardzija, M., 2012. Intrauterine ozone treatment of retained fetal membrane in Simmental cows. Anim. Reprod. Sci. 134, 119-124. https://doi.org/10.1016/j.anireprosci.2012.08.023.

Drillich, M., Beetz, O., Pfützner, A., Sabin, M., Sabin, H.J., Kutzer, P., Nattermann, H., Heuwieser, W., 2001. Evaluation of a systemic antibiotic treatment of toxic puerperal metritis in dairy cows. J. Dairy Sci. 84, 2010-2017. https://doi.org/ 10.3168/jds.S0022-0302(01)74644-9.

Drillich, M., Pfützner, A., Sabin, H.-J., Sabin, M., Heuwieser, W., 2003. Comparison of two protocols for the treatment of retained fetal membranes in dairy cattle. Theriogenology 59, 951-960. https://doi.org/10.1016/j.anireprosci.2019.04.013.

Drillich, M., Mahlstedt, M., Reichert, U., Tenhagen, B.A., Heuwieser, W., 2006 a. Strategies to improve the therapy of retained fetal membranes in dairy cows. J. Dairy Sci. 89, 627-635. https://doi.org/10.3168/jds.S0022-0302(06)72126-9.

Drillich, M., Reichert, U., Mahlstedt, M., Heuwieser, W., 2006b. Comparison of two strategies for systemic antibiotic treatment of dairy cows with retained fetal membranes: preventive vs. selective treatment. J. Dairy Sci. 89, 1502-1508. https:// doi.org/10.3168/jds.S0022-0302(06)72217-2.

Dubuc, J., Duffield, T.F., Leslie, K.E., Walton, J.S., LeBlanc, S.J., 2010. Risk factors for postpartum uterine diseases in dairy cows. J. Dairy Sci. 93, 5764-5771. https://doi. org/10.3168/jds.2010-3429.

Dubuc, J., Duffield, T.F., Leslie, K.E., Walton, J.S., LeBlanc, S.J., 2011. Effects of postpartum uterine diseases on milk production and culling in dairy cows. J. Dairy Sci. 94, 1339-1346. https://doi.org/10.3168/jds.2010-3758.

Eiler, H., Fecteau, K.A., 2007. Retained placenta. In: Yougquist, R.S., Threlfall, W.R. (Eds.), Current Therapy in Large Animal Theriogenology. Elsevier Inc., Missouri, pp. 345-354. https://doi.org/10.1136/bmj.2.4530.709-c.

Fourichon, C., Seegers, H., Malher, X., 2000. Effect of disease on reproduction in the dairy cow: a meta-analysis. Theriogenology 26, 307-320. https://doi.org/10.1108/ 09596119910272739.
Frazer, G.S., 2005. A rational basis for therapy in the sick postpartum cow. Vet. Clin. North Am. - Food Anim. Pract. 21, 523-568. https://doi.org/10.1016/j. cvfa.2005.03.005.

Garcia, A., Barth, A.D., Mapletoft, R.J., 1992. The effects of treatment with cloprostenol or dinoprost within one hour of induced parturition on the incidence of retained placenta in cattle. Can. Vet. J. 33, 175-183.

Gilbert, R.O., 2018. Reproductive diseases. In: Peek, S.F., Divers, T.J. (Eds.), Ed.): Rebhun's Diseases of Dairy Cattle, 3rd ed. Elsevier Inc., pp. 466-507. https://doi. org/10.1016/B978-0-323-39055-2.00009-7

Gohary, K., LeBlanc, S.J., 2018. Cost of retained fetal membranes for dairy herds in the United States. J. Am. Vet. Med. Assoc. 252, 1485-1489. https://doi.org/10.2460/ javma.252.12.1485.

Goshen, T., Shpigel, N.Y., 2006. Evaluation of intrauterine antibiotic treatment of clinical metritis and retained fetal membranes in dairy cows. Theriogenology 66, 2210-2218. https://doi.org/10.1016/j.theriogenology.2006.07.017.

Gröhn, Y.T., Rajala-Schultz, P.J., 2000. Epidemiology of reproductive performance in dairy cows. Anim. Reprod. Sci. 60-61, 605-614. https://doi.org/10.1016/S03784320(00)00085-3.

Gröhn, Y.T., Eicker, S.W., Hertl, J.A., 1995. The association between previous 305-day milk yield and disease in New York state dairy cows. J. Dairy Sci. 78, 1693-1702. https://doi.org/10.3168/jds.S0022-0302(95)76794-7.

Guérin, P., Thiébault, J.J., Delignette-Muller, M.L., Badinand, F., Bosc, L., Ménézo, Y., 2004. Effect of injecting collagenase into the uterine artery during a caesarean section on the placental separation of cows induced to calve with dexamethasone. Vet. Rec. 154, 326-328. https://doi.org/10.1136/vr.154.11.326.

Gustin, P., 2020. Antibactériens. In: Gustin, P. (Ed.), Répertoire commenté des médicaments à usage vétérinaire. CBIP-vétérinaire, Bruxelles, pp. 1-25.

Haimerl, P., Arlt, S., Borchardt, S., Heuwieser, W., 2017. Antibiotic treatment of metritis in dairy cows-a meta-analysis. J. Dairy Sci. 100, 3783-3795. https://doi.org/ 10.3168/jds.2016-11834.

Hehenberger, E.M., Doherr, M.G., Bodmer, M., Steiner, A., Hirsbrunner, G., 2015. Diagnosis and therapy of retained fetal membranes, puerperal metritis and clinical endometritis in cattle: results of the online-survey among swiss practitioners. | retained fetal membranes. Schweiz. Arch. Tierheilkd. 157, 497-502. https://doi. org/10.17236/sat00032.

Imhof, S., Luternauer, M., Hüsler, J., Steiner, A., Hirsbrunner, G., 2019. Therapy of retained fetal membranes in cattle: comparison of two treatment protocols. Anim. Reprod. Sci. 206, 11-16. https://doi.org/10.1016/j.anireprosci.2019.04.013.

Kaitu'u, T.J., Shen, J., Zhang, J., Morison, N.B., Salamonsen, L.A., 2005. Matrix metalloproteinases in endometrial breakdown and repair: functional significance in a mouse model1. Biol. Reprod. 73, 672-680. https://doi.org/10.1095/biolreprod.105, 042473.

Kimura, K., Goff, J.P., Kehrli, M.E., Reinhardt, T.A., 2002. Decreased neutrophil function as a cause of retained placenta in dairy cattle. J. Dairy Sci. 85, 544-550. https://doi. org/10.3168/jds.S0022-0302(02)74107-6.

Lehtolainen, T., Shwimmer, A., Shpigel, N.Y., Honkanen-Buzalski, T., Pyörälä, S., 2003. In vitro antimicrobial susceptibility of Escherichia coli isolates from clinical bovine mastitis in Finland and Israel. J. Dairy Sci. 86, 3927-3932. https://doi.org/10.3168/ jds.S0022-0302(03)74001-6.

Lima, F.S., Vieira-Neto, A., Vasconcellos, G.S.F.M., Mingoti, R.D., Karakaya, E., Solé, E., Bisinotto, R.S., Martinez, N., Risco, C.A., Galvão, K.N., Santos, J.E.P., 2014. Efficacy of ampicillin trihydrate or ceftiofur hydrochloride for treatment of metritis and subsequent fertility in dairy cows. J. Dairy Sci. 97, 5401-5414. https://doi.org/ 10.3168/jds.2013-7569.

Moller, K., 1967. Retained foetal membranes in dairy herds in the huntly district. N. Z. Vet. J. 15, 239. https://doi.org/10.1080/00480169.1967.33735.

Musah, A.L., Schwabe, C., Willham, R.L., Anderson, L.L., 1987. Induction of parturition, progesterone secretions, and delivery of placenta in beef heifers given relaxin and cloprostenol or dexa- methasone. Biol. Reprod. 39, 797-803.

Ordell, A., Unnerstad, H.E., Nyman, A., Gustafsson, H., Båge, R., 2016. A longitudinal cohort study of acute puerperal metritis cases in Swedish dairy cows. Acta Vet. Scand. 58, 1-8. https://doi.org/10.1186/s13028-016-0257-9.

Palomares, R.A., Gutiérrez, J.C., Portillo, G., Boscan, J.C., Montero, M., López, Y., Maxwell, H.S., Carson, R.L., Soto, E., 2010. Oxytocin treatment immediately after 
calving does not reduce the incidence of retained fetal membranes or improve reproductive performance in crossbred Zebu cows. Theriogenology 74, 1414-1419. https://doi.org/10.1016/j.theriogenology.2010.06.013.

Peters, A.R., Laven, R.A., 1996. Treatment of bovine retained placenta and its effects. Vet. Rec. 139, 535-539. https://doi.org/10.1136/vr.139.22.535.

Pohl, A., Bertulat, S., Borchardt, S., Burfeind, O., Heuwieser, W., 2016. Randomized, controlled clinical trial on the efficacy of nonsteroidal antiinflammatory drugs for the treatment of acute puerperal metritis in dairy cows. J. Dairy Sci. 99, 8241-8249. https://doi.org/10.3168/jds.2015-10775.

Pyörälä, S., Taponen, J., Katila, T., 2014. Use of antimicrobials in the treatment of reproductive diseases in cattle and horses. Reprod. Domest. Anim. 49, 16-26. https://doi.org/10.1111/rda.12324.
Sheldon, I.M., 2004. The postpartum uterus. Vet. Clin. North Am. - Food Anim. Pract. 20, 569-591. https://doi.org/10.1016/j.cvfa.2004.06.008.

Sheldon, I.M., Cronin, J., Goetze, L., Donofrio, G., Schuberth, H.J., 2009. Defining postpartum uterine disease and the mechanisms of infection and immunity in the female reproductive tract in cattle. Biol. Reprod. 81, 1025-1032. https://doi.org/ 10.1095/biolreprod.109.077370.

Threlfall, W.R., 2007. Retained fetal membranes. In: Youngquist, R.S., Threlfall, W.R. (Eds.), Current Therapy in Large Animal Theriogenology, 2nd ed. Elsevier Inc., Missouri, pp. 107-113. https://doi.org/10.1002/9781118833971. ch49.

Vandeplassche, M., Bouters, R., 1982. The impact of gynaecological and obstetrical problems resulting out of pregnancy and parturition. In: Karg, H.S. (Ed.), Factors Affecting Fertility in the Post Partum Cow. Martinus Nijhoff Publishers, The Hague, pp. $30-44$. 